\title{
@ Health and Climate Change 6
}

\section{Public health benefits of strategies to reduce greenhouse-gas emissions: overview and implications for policy makers}

\author{
Andy Haines, AnthonyJ McMichael, Kirk R Smith, lan Roberts, James Woodcock, Anil Markandya, Ben G Armstrong, Diarmid Campbell-Lendrum, \\ Alan D Dangour, Michael Davies, Nigel Bruce, Cathryn Tonne, Mark Barrett, Paul Wilkinson*
}

Lancet 2009; 374: 2104-14 Published Online November 25, 2009 DOl:10.1016/S0140-

6736(09)61759-1

This is the sixth in a Series of

six papers about health and climate change

*Based on the work of the Task Force on Climate Change Mitigation and Public Health, which is described in the preceding papers of this Series. Members listed at end of paper

London School of Hygiene and Tropical Medicine, London, UK (Prof A Haines FMedSci, Prof I Roberts PhD,

JWoodstock MSC,

Prof B G Armstrong PhD, $A$ D Dangour PhD, C Tonne ScD,

PWilkinson FR(P); National Centre for Epidemiology and Population Health, Australian National University, Canberra, ACT, Australia (Prof A J McMichael PhD); School of Public Health, University of California, Berkeley, CA, USA (Prof K R Smith PhD); Ikerbasque, BC3 (Basque Centre for Climate Change), Bilbao, Spain

(Prof A Markandya PhD); University of Bath, Bath, UK

(Prof A Markandya); Public Health and Environment (PHE), World Health Organization, Geneva, Switzerland

(D Campbell-Lendrum PhD); School of Population, Community and Behavioural Sciences, University of Liverpool, Liverpool, UK (N Bruce PhD); Bartlett School of Graduate Studies, University College London, London, UK (Prof M Davies PhD); and UCL Energy Institute, London, UK (M Barrett PhD)

Correspondence to: Prof Andy Haines, London School of Hygiene and Tropical Medicine, Keppel Street, London WC1E 7HT, UK andy.haines@lshtm.ac.uk

This Series has examined the health implications of policies aimed at tackling climate change. Assessments of mitigation strategies in four domains - household energy, transport, food and agriculture, and electricity generation-suggest an important message: that actions to reduce greenhouse-gas emissions often, although not always, entail net benefits for health. In some cases, the potential benefits seem to be substantial. This evidence provides an additional and immediate rationale for reductions in greenhouse-gas emissions beyond that of climate change mitigation alone. Climate change is an increasing and evolving threat to the health of populations worldwide. At the same time, major public health burdens remain in many regions. Climate change therefore adds further urgency to the task of addressing international health priorities, such as the UN Millennium Development Goals. Recognition that mitigation strategies can have substantial benefits for both health and climate protection offers the possibility of policy choices that are potentially both more cost effective and socially attractive than are those that address these priorities independently.

\section{Introduction}

Climate change threatens the health of human populations worldwide, but particularly in low-income countries. ${ }^{1}$ These adverse health consequences are among the many important reasons why governments need collectively to act with resolution and urgency to reduce global greenhouse-gas emissions. What has been less widely understood, however, is that policies to

\section{Key messages}

- Many measures to reduce greenhouse-gas emissions in the sectors of household energy, transport, food and agriculture, and electricity generation have ancillary health benefits (or health co-benefits), which are often substantial.

- The health co-benefits resulting from such measures can help address existing global health priorities, such as child mortality from acute respiratory infections, ischaemic heart disease in adults, and other non-communicable diseases.

- Improvement of access to affordable, clean energy (especially for disadvantaged populations), together with other appropriate strategies in several sectors, can contribute to a reduction in the risk of dangerous climate change while improving health, reducing poverty, and supporting development

- Specific policies that can reduce greenhouse-gas emissions and result in health benefits include increased active transport (walking and cycling) and reduced private-car use in urban settings, increased uptake of improved cookstoves in low-income countries, reduced consumption of animal products in high-consumption settings, and generation of electricity from renewable or other low-carbon sources rather than from fossil fuels, particularly coal.

(Continues in next column) reduce greenhouse-gas emissions (climate change mitigation policies) could often have more immediate and potentially large effects on population health. These ancillary effects are important not only because they can provide an additional rationale to pursue mitigation strategies, but also because progress has been slow to address international health priorities such as the UN Millennium Development Goals (MDGs) ${ }^{2}$ and reductions in health inequities. Mitigation measures can thus offer an opportunity not only to reduce the risks of climate change but also, if well chosen and implemented, to deliver improvements in health-the so-called cobenefits of mitigation, although not all effects are necessarily positive.

(Continued from previous column)

- The varying costs of implementation of such strategies can be offset at least partly by the benefits to health and development, and these co-benefits should be taken into account in international negotiations.

- Some measures, however, can have negative health effects; therefore assessment of health effects of greenhouse-gas mitigation strategies is important.

- Mechanisms to transfer resources for clean development from high-income to low-income countries should take into account health consequences of the technologies and strategies in decisions about priorities for funding

- The methods for assessing the health effects of mitigation strategies for climate change outlined in this Series should be further developed and applied, to inform policy making.

- Health professionals have an important role in the design of a low-carbon economy, motivated by evidence of the projected benefits to public health 


\begin{tabular}{|c|c|c|c|c|c|c|}
\hline & $\begin{array}{l}\text { Country, } \\
\text { city, or } \\
\text { region }\end{array}$ & Mechanism of health effect & Main health outcome(s) affected & $\begin{array}{l}\text { Approximate reduction in } \\
\text { burden of disease (in DALYs } \\
\text { per million population) }\end{array}$ & $\begin{array}{l}\text { Approximate cost } \\
\text { (US\$) }\end{array}$ & $\begin{array}{l}\text { Potential adverse health } \\
\text { effects }\end{array}$ \\
\hline \multicolumn{7}{|l|}{ Household energy } \\
\hline $\begin{array}{l}\text { Housing-related } \\
\text { energy efficiency }\end{array}$ & UK & $\begin{array}{l}\text { Changes in indoor pollution (radon, } \\
\text { particles, carbon monoxide, } \\
\text { second-hand tobacco smoke); } \\
\text { mould; winter indoor temperature }\end{array}$ & $\begin{array}{l}\text { Lung cancer (radon), } \\
\text { cardiovascular disease, acute } \\
\text { and chronic respiratory disease, } \\
\text { winter/cold-related death }\end{array}$ & 850 & $\begin{array}{l}\$ 5000-50000 \text {, one-off } \\
\text { cost per household, } \\
\text { off-set by lower } \\
\text { recurrent fuel costs* }\end{array}$ & $\begin{array}{l}\text { Increase in pollution } \\
\text { concentration from reduced } \\
\text { ventilation and increased } \\
\text { cold-related risk from cooler } \\
\text { indoor temperatures }\end{array}$ \\
\hline $\begin{array}{l}\text { Clean-burning } \\
\text { cookstoves }\end{array}$ & India & $\begin{array}{l}\text { Changes in exposure to indoor } \\
\text { pollution }\end{array}$ & $\begin{array}{l}\text { Acute lower respiratory tract } \\
\text { infection, ischaemic heart disease, } \\
\text { chronic obstructive respiratory } \\
\text { disease }\end{array}$ & 12500 & $\begin{array}{l}\$ 50 \text { cost per stove, } \\
\text { perhaps every } 5 \text { years, } \\
\text { continual fuel savings } \\
\text { and/or time savings }\end{array}$ & No adverse effects identified \\
\hline \multicolumn{7}{|l|}{ Transport system } \\
\hline $\begin{array}{l}\text { Lower carbon and } \\
\text { more active } \\
\text { transport }\end{array}$ & $\begin{array}{l}\text { London, } \\
\text { UK }\end{array}$ & $\begin{array}{l}\text { Altered air pollution, changes in } \\
\text { injury risk, changes in physical } \\
\text { activity }\end{array}$ & $\begin{array}{l}\text { Ischaemic heart disease, } \\
\text { cerebrovascular disease, dementia, } \\
\text { breast cancer, lung cancer, colon } \\
\text { cancer, diabetes, depression, road } \\
\text { traffic injuries }\end{array}$ & 7400 & $\begin{array}{l}\text { Unclear: possibly } \\
\text { negative (cost-saving) } \\
\text { to households }\end{array}$ & $\begin{array}{l}\text { Trade-off between reduced } \\
\text { road traffic danger from less } \\
\text { motor travel and increased } \\
\text { exposure to remaining danger } \\
\text { from more walking and cycling }\end{array}$ \\
\hline $\begin{array}{l}\text { Lower carbon and } \\
\text { more active } \\
\text { transport }\end{array}$ & $\begin{array}{l}\text { Delhi, } \\
\text { India }\end{array}$ & As for UK & $\begin{array}{l}\text { Ischaemic heart disease, road traffic } \\
\text { injuries, cerebrovascular disease, } \\
\text { lung cancer, diabetes, depression }\end{array}$ & 13000 & As for UK & As for UK \\
\hline \multicolumn{7}{|c|}{ Food and agriculture } \\
\hline $\begin{array}{l}\text { Lowering } \\
\text { consumption of } \\
\text { animal products }\end{array}$ & UK & Lower saturated fat intake & Ischaemic heart disease & 2900 & $\begin{array}{l}\text { Unclear: possibly } \\
\text { negative (cost-saving) } \\
\text { to households and } \\
\text { society }\end{array}$ & $\begin{array}{l}\text { Childhood growth and } \\
\text { development from reduced } \\
\text { animal-product consumption } \\
\text { (low-income countries) }\end{array}$ \\
\hline $\begin{array}{l}\text { Lowering } \\
\text { consumption of } \\
\text { animal products }\end{array}$ & $\begin{array}{l}\text { São Paulo } \\
\text { city, Brazil }\end{array}$ & As for UK & As for UK & 2200 & As for UK & As for UK \\
\hline \multicolumn{7}{|c|}{ Electricity generation } \\
\hline $\begin{array}{l}\text { Low-carbon fuels/ } \\
\text { technologies }\end{array}$ & $\begin{array}{l}\text { European } \\
\text { Union }\end{array}$ & Reduced (particulate) air pollution & $\begin{array}{l}\text { Cardiopulmonary mortality, lung } \\
\text { cancer, occupational mortality }\end{array}$ & 100 & $\begin{array}{l}\$ 140 \text { per tonne carbon } \\
\text { dioxide }\end{array}$ & $\begin{array}{l}\text { Increase in fuel poverty from } \\
\text { higher electricity costs, health } \\
\text { risks from nuclear generation } \\
\text { and carbon capture and storage }\end{array}$ \\
\hline $\begin{array}{l}\text { Low-carbon fuels/ } \\
\text { technologies }\end{array}$ & China & As for European Union & As for European Union & 550 & $\begin{array}{l}\$ 70 \text { per tonne carbon } \\
\text { dioxide }\end{array}$ & As for European Union \\
\hline $\begin{array}{l}\text { Low-carbon fuels/ } \\
\text { technologies }\end{array}$ & India & As for European Union & As for European Union & 1500 & $\begin{array}{l}\$ 40 \text { per tonne carbon } \\
\text { dioxide }\end{array}$ & As for European Union \\
\hline
\end{tabular}

\section{Overview of sectoral assessments}

This Series focused on the health effects of mitigation strategies in four sectors-household energy, ${ }^{3}$ transport, ${ }^{4}$ food and agriculture, ${ }^{5}$ and electricity generation ${ }^{6}$ - using examples from high-income and low-income or middleincome settings. In each sector, the potential links between reduction in greenhouse-gas emissions and health seem to be strong. The methods and results are summarised in the table and figures 1 and 2. A fifth paper $^{7}$ in the Series both reviews and provides new evidence for the health effects of short-lived greenhouse pollutants, which are emitted from several sectors.

Figures 1 and 2 show the assessments of the effect of mitigation scenarios both in terms of changes in health (disability-adjusted life-years [DALYs] saved) and reductions in carbon dioxide equivalent $\left(\mathrm{CO}_{2} \mathrm{e}\right)$ emissions per million of the 2010 population, and in terms of absolute numbers (ie, the total change for the relevant populations as a whole). It is important to note that the sector-specific and setting-specific results shown in figures 1 and 2 are not exactly comparable with each other, since each assessment had its own set of assumptions and detailed methods of estimation. The results should therefore be interpreted only as broad indications of magnitude of effect.

For the case studies of the household energy and food and agriculture sectors (figure 1), the estimated health effects of strategies to reduce greenhouse gases were calculated from the difference between baseline (2010) exposures and those that would occur under mitigation, with the assumption that circumstances are otherwise held constant at 2010 conditions. This approach has the advantage of reducing the need for uncertain projections, and makes the stand-alone mitigation effect clear, but it takes no account of potentially important trends over time, particularly in exposure, which could arise as a 


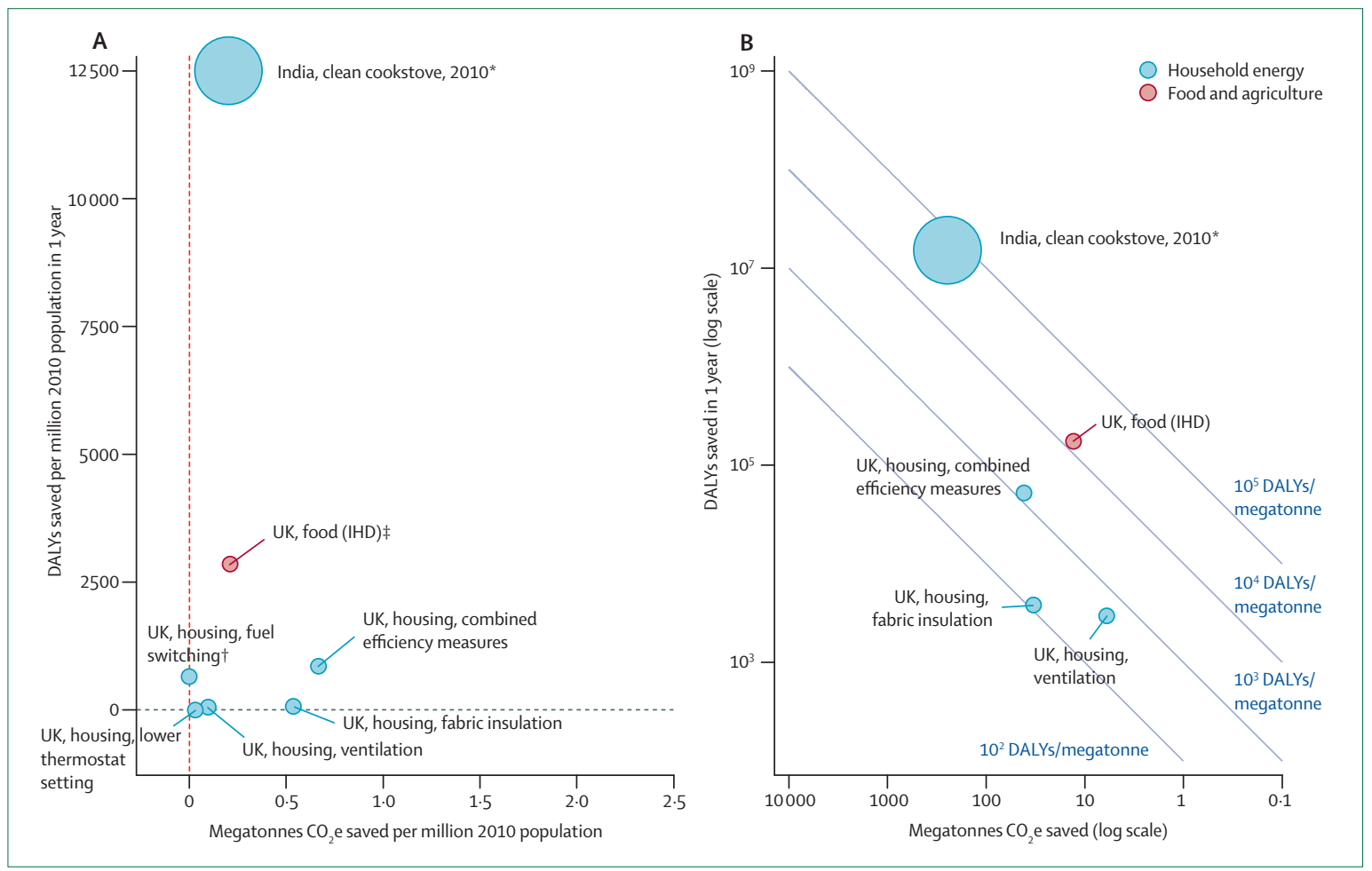

Figure 1: Attributable reduction in disease burden and in carbon dioxide equivalent emissions for household energy and food and agriculture case studies (A) Disability-adjusted life-years (DALYS) saved and carbon dioxide equivalent $\left(\mathrm{CO}_{2} \mathrm{e}\right)$ reduction per million of the 2010 population. (B) Reduction in total of DALYS and $\mathrm{CO}_{2}$ e for each country. Circle sizes proportional to population of the relevant country. DALYs saved are based on attributable burden calculations comparing the health of the 2010 population with and without the specified mitigation measures. Scenario results with negative or zero change are not plotted in B. IHD=ischaemic heart disease. *Alternative calculations based on the staged implementation of the cookstove programme over 10 years are given in the first paper in this Series. ${ }^{3}$ The reduction in emissions of greenhouse gases is based mainly on non-carbon-dioxide pollutants, and the carbon dioxide equivalence should be interpreted as approximate. †Zero change has been shown, but a net change in carbon dioxide emissions is probably dependent on the alternative primary fuel sources. The São Paulo city case study was not included because of uncertainties about livestock-related greenhouse-gas emissions. $¥$ The changes shown in greenhouse-gas emissions are those occurring directly from the UK only, and do not include possible emission savings from countries that produce livestock for consumption in the UK. About $20-30 \%$ of the livestock products consumed in the UK are imported.

result of policies or societal changes unrelated to climate change mitigation.

The assessment of mitigation measures in the electricity generation and transport sectors (figure 2), by contrast, used projections of exposures to 2030, partly because models were readily available to the investigators, but also because in these sectors the pace of technological and societal development is likely to result in large changes in exposures during coming decades, especially in countries such as India and China. Thus, we calculated the effects on health for a 2010 population using the differences in estimated exposures in 2030 between business-as-usual and mitigation scenarios.

Most, although not all, of the mitigation scenarios are estimated to have net benefit for population health, at least in terms of the direct pathways modelled. In some cases, notably the cleaner cookstoves in India, and sustainable transport based on increased participation in walking and cycling together with much lower car use in Delhi, the benefits seem substantial-more than 10000 DALYs per million of the 2010 population. These scenarios and the reduced saturated fat intake example for the UK also had large reductions per megatonne of $\mathrm{CO}_{2}$ e saving-greater than 10000 DALYs saved in 1 year per megatonne $\mathrm{CO}_{2} / \mathrm{CO}_{2} \mathrm{e}$ emissions reduction (figures 1 and 2). These interventions affect the risks of major causes (large burdens) of mortality and morbidity, which explains the large reductions in DALYs per million population suggested for these scenarios. The transport case studies for Delhi all show an increase in emissions compared with 2010 because of the substantial projected rise in population and, in some scenarios, motorised transport, compared with 2010, although all three scenarios represent savings of $\mathrm{CO}_{2}$ emissions compared with 2030 business-as-usual projections. These $\mathrm{CO}_{2}$ emission savings would be substantial for the scenarios that entail less private motorised travel.

These overall positive changes disguise some potential negative health effects that need to be guarded against—eg, possible negative nutritional consequences of decreased consumption of livestock products on childhood growth and development in low-consumption settings; and possible increased exposure to radon, mould, and indoor air pollution due to reduced 


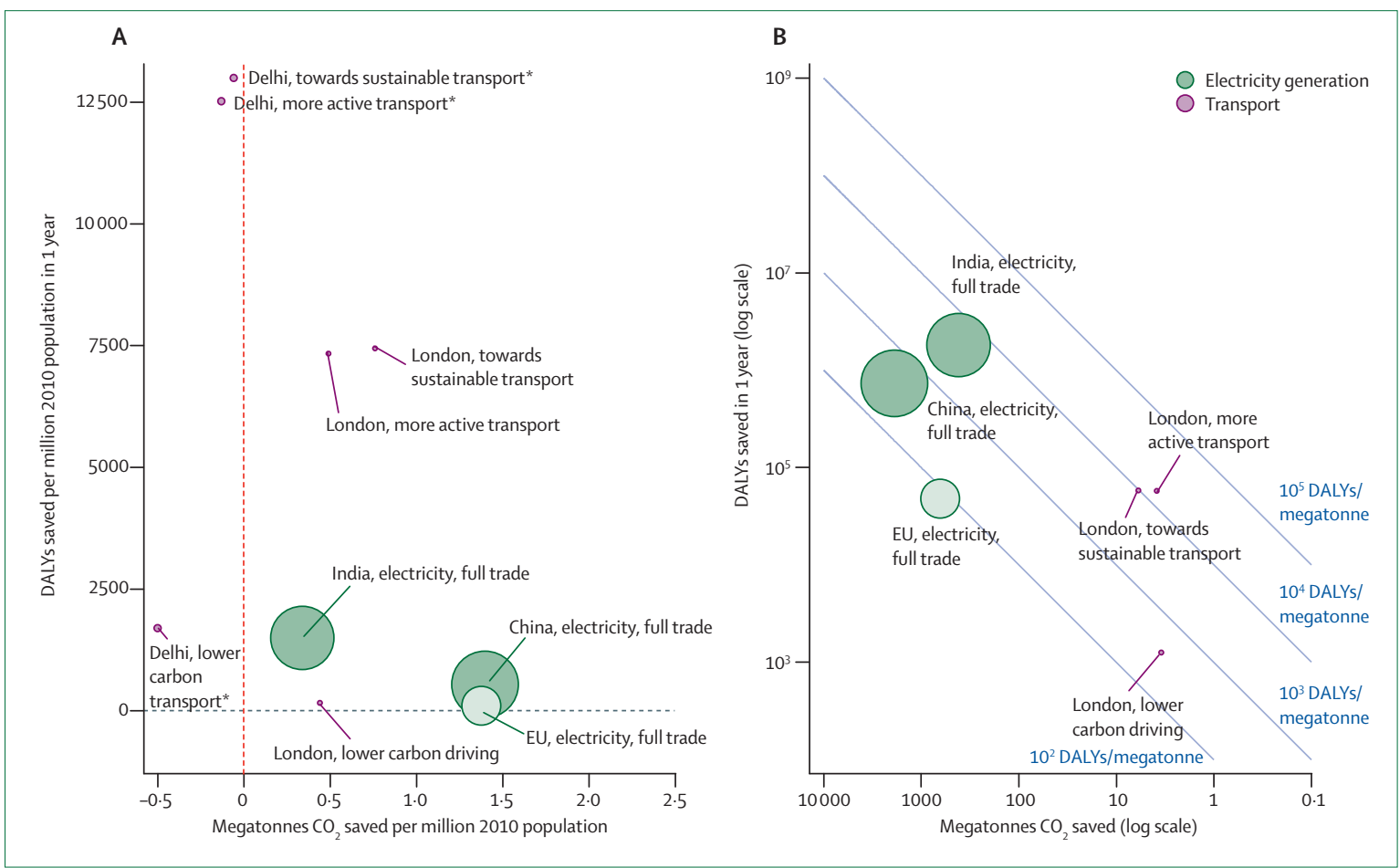

Figure 2: Attributable reduction in disease burden and in carbon dioxide equivalent emissions for electricity generation and transport case studies (A) Disability-adjusted life-years (DALYS) and carbon dioxide $\left(\mathrm{CO}_{2}\right)$ reduction per million of the 2010 population. (B) Reduction in total of DALYs and $\mathrm{CO}_{2}$ for each country, city, or region. Circle sizes proportional to population of the relevant country, city, or region. Estimates of DALYs saved based on attributable burden calculations comparing 2030 mitigation scenarios with 2030 business-as-usual scenarios. Scenario results with negative or zero change are not plotted in B. EU=European Union. *Although there are small increases (negative savings) in $\mathrm{CO}_{2}$ emissions for the transport mitigation scenarios in Delhi compared with 2010 all three scenarios entail appreciable savings of $\mathrm{CO}_{2}$ emissions against business-as-usual projections. The reductions per million of the 2010 population against business-as-usual projections are: 0.14 megatonnes for lower carbon driving, 0.52 megatonnes for more active transport, and 0.58 megatonnes for the scenario of towards sustainable transport.

household ventilation rates in high-income settings. Furthermore, while decreased use of motor vehicles could lead to less road traffic danger, thus reducing road traffic injuries, more walking and cycling could increase exposure to remaining road traffic danger, thus increasing road traffic injuries. The trade-off between these effects will vary by setting but can be improved by use of appropriate policies. Measures can be taken to protect against such adverse consequences where these are recognised, underscoring the value of modelling studies, together with assessment of interventions, to test and refine major policy decisions.

The extent of changes in emissions, local environmental conditions, and associated behaviours has inevitable uncertainties that affect what could be achieved in complex real-world settings. Reduced greenhouse-gasemitting electricity generation, and increased household energy efficiency in the UK, seem to have modest although still important benefits for health, but greatly affect greenhouse-gas emissions. Economic costs are also important in choosing between mitigation strategies, but their assessment is not straightforward because of methodological challenges (panel 1). The costs of changes, particularly in the agriculture and transport sectors, are very difficult to assess because implementation could entail a complicated combination of changes in taxation, subsidy, regulation, infrastructure development, and many other policies, with wide-ranging indirect effects. Account also needs to be taken of who pays the costs of the policies and who benefits from potential savings - eg, the cost of efficiency interventions and the savings in fuel costs that might follow. Identification of all these factors is a major exercise in its own right, warranting further research.

Nevertheless, the costs of the different interventions can be considered in broad terms (table). An improved cookstove programme in India, for example, would entail a yearly cost per household of, at most, a few tens of US dollars and continual savings in terms of expenditure that can take the form of cash outlays for fuel or time outlays that have an opportunity cost. Stove costs, particularly for the poorest households, can be reduced via carbon finance to support subsidies or other pro-poor financial instruments. However, a household energy efficiency programme in the UK, to achieve the exacting standards specified, would cost in the range \$5000-50000 per dwelling, resulting in reduced fuel bills by an average of around $\$ 500$ a year at current prices, but much more as fossil-fuel and electricity prices increase. Reductions, relative to business as usual, in greenhouse-gas emissions 
from electricity generation by the full-trade modelthe national targets for which can be met through buying and selling of emissions permits in a global market for such permits-are estimated to range in cost from a few tens of dollars per tonne of $\mathrm{CO}_{2}$ in India to more than $\$ 100$ per tonne in the UK. The changes in transport, which achieve substantial increases in walking and cycling with reductions in urban motor vehicle use, and the changes in dietary consumption patterns, are both potentially cost-saving to households and society at present prices, although policies to bring about these changes will entail some costs not determined in our analysis.

The UK National Health Service (NHS) spends about $\$ 5000$ a minute on treating diseases that could be

Panel 1: Methodological challenges

One of the key challenges is development of credible scenarios of greenhouse-gas emissions under mitigation and business-as-usual projections during future decades. This challenge is especially difficult in the case of societies undergoing rapid development, in which, for example, transport patterns could change substantially in a short time with major implications for public health. Public health researchers should work closely with those involved in research and strategic planning in the relevant sector to ensure that the scenarios that are used are grounded on the best available evidence about probable trends, and that the assumptions on which they are based are made transparent. The selection of the business-as-usual scenario and the assumptions underlying it are important and can affect the estimates of the health co-benefits dependent on, for example, what assumptions are made about reductions in air pollution as a result of legislation or the introduction of cleaner engines unrelated to policies for climate change. Assumptions about underlying trends in the prevalence and mortality from disorders such as ischaemic heart disease can materially affect estimates of effect. Sensitivity analyses exploring several potential assumptions about future trends and relations between relevant policies and health outcomes are needed. Estimates of effect should be revisited as new scientific insights into exposure-response relations or technological options for reduction of greenhouse-gas emissions become available.

Cost-benefit or, more commonly, cost-effectiveness analysis, is widely used to assess health interventions. In the particular context of health co-benefits of climate change, cost-benefit analysis is not especially useful since such analysis would entail comparison of the benefits of reductions in emissions (health benefits in the short to medium term as well as those arising in the long term from reduced greenhouse gases) against the costs entailed in achieving those reductions. Integrated assessment models that incorporate reductions in greenhouse-gas emissions across a range of sectors and strategies should take into account health co-benefits.

(Continues on next page) prevented by regular physical activity. ${ }^{9}$ Reducing this expenditure and other benefits would help to offset any costs of implementation. Furthermore, the potential for benefits could increase in the future-eg, by 2050, modelling undertaken for the Foresight report ${ }^{10}$ suggests that $60 \%$ of adult men, $50 \%$ of adult women, and about $25 \%$ of all children younger than 16 years could be obese. The NHS costs attributable to overweight and obesity are projected to double to $£ 10$ billion per year by 2050 . The wider costs to society and business are estimated to reach about $£^{50}$ billion per year (at present prices).

In terms of strategic choices, the greatest health gains seem likely to result from changes towards active transport, and from diets that are low in animal source foods, at least for adult populations in high-income countries. The clean cookstove programme for India also seems a priority low-cost intervention for its public health benefits, even though its effect on greenhousepollutant emissions is less easily determined (and mainly relates to non- $\mathrm{CO}_{2}$ greenhouse-gas emissions: methane, carbon monoxide, and black and organic carbon in circumstances in which biomass fuel is renewably harvested, resulting in no net $\mathrm{CO}_{2}$ emissions).

The evidence suggests that very substantial health gains are achievable (in addition to substantial reductions in greenhouse gases and black carbon emissions) for little cost by improvement of the combustion of solid household fuels (coal and biomass) in confined and unventilated housing in many low-income countries. Household exposure to indoor air pollutants from inefficient or unventilated combustion-which is widespread in China, South Asia, and much of subSaharan Africa and Latin America-causes an estimated 1.6 million premature deaths per year, predominantly in women and children. ${ }^{11}$ Although interventions in electricity generation and in household energy efficiency in high-income countries have lower benefits in terms of DALYs saved per head than they do in low-income countries, they nonetheless seem to bring about appreciable public health benefits if implemented well.

In the medium term the world does not have the luxury of choosing one intervention over another, since only the combined effect of all these mitigation actions, in addition to many others, will achieve the substantial reduction in greenhouse-gas emissions that is needed. Societies, however, have the choice of which to pursue most vigorously at first, and of how to prioritise the use of resources to avert climate change compared with addressing present social priorities-decisions that can be informed by health cost-effectiveness analyses. Examples include cutting transport-related greenhousegas emissions by encouraging active transport and reducing car use in urban centres rather than by changes in technology and, (an example that affects international cooperation and development) a transition to low-greenhouse-gas electricity generation in countries such as India and China compared with Europe and 
North America. This benefit provides an incentive for early action in countries such as India and China, although clearly it is not an argument for Europe and North America to postpone the urgent reductions in their own emissions that are needed.

The fifth paper in the Series ${ }^{7}$ draws attention to the importance of a set of short-lived greenhouse pollutants that are emitted in several sectors and are often left out of policy and public discussions: sulphate and black carbon particles and tropospheric ozone. All have adverse health effects and all are climate active. The importance of paying much closer attention to them in mitigation policy relates to the fact that changes in emission rates are quickly reflected in atmospheric concentrations. Cutting the responsible emissions therefore has immediate effects on climate warming. At the same time, there are questions of whether different types of particles from different sources may be more or less detrimental to health. Evidence for the adverse health effects of combustion products and their large global health burdens is well established, ${ }^{11}$ but there is uncertainty whether sulphates, which largely derive from power and transport sectors, and black carbon, which is produced by the incomplete combustion of biomass and fossil fuels, mainly in the household and transport sectors, are equally important for health.

New evidence is presented in the fifth paper $^{7}$ in this Series on the health effects of elemental carbon, the closest equivalent to the metric of black carbon used by climate scientists. This analysis finds some evidence that particles of elemental and black carbon cause more mortality risk by mass than do undifferentiated fine particles, but also pronounced interaction with ozone in the risk models, leaving the issue unsettled. For sulphates, however, the evidence from both reviews and the new study is more consistent and indicates, by mass, sulphate particles are no less damaging than undifferentiated fine particles and might indeed be somewhat more so. These findings have important implications for mitigation efforts.

Since interventions to reduce black carbon emissions will also control the associated organic carbon particles, which are health-damaging but mildly cooling, the net climate effect will depend on the ratio of these two particle types in the original mixture. Strategies to reduce sulphate concentrations, however, although desirable from a public health perspective, could exacerbate climate change in the near term because of a loss of cooling aerosols, implying that even deeper cuts in greenhouse-gas emissions might be needed than are proposed in present official targets if dangerous climate change is to be avoided.

Ozone concentrations are rising worldwide due to increasing anthropogenic precursor emissions including methane, the second most important greenhouse gas. Ozone is not only a powerful greenhouse gas, but is increasingly implicated as a cause of premature
(Continued from previous page)

In the design of mitigation measures, reduction targets for greenhouse gases at different periods are often taken as fixed, and a cost-effectiveness analysis allows us to choose the least cost options for meeting these targets. The main purpose of mitigation activity is to curb greenhouse-gas emissions. Incidental, direct gains to health are an additional bonus to the value to the mitigation action, and if these benefits can be valued in monetary terms they can be offset against the costs of these actions, giving a resulting net cost per tonne of greenhouse gases reduced. This analysis has been done extensively for interventions reducing carbon dioxide and other greenhouse pollutants from electricity and household stoves. However, the cost-effectiveness analysis can be difficult to do. Some of the issues that have been raised include:

- How should the indefinitely continuing stream of health gain be valued, especially reductions in premature mortality? Is it ethical to take different values for this benefit dependent on how wealthy a country is?

- Is discounting of future gains relevant, or would it undervalue the mitigation and introduce intergenerational inequity?

- How should benefits be traded against costs? For example, reduction of car use and increase of active transport in cities might reduce fuel bills and vehicle ownership costs for households but might increase travel times, at least until land use and trip destinations change.

- How should direct and indirect economic effects of major social change be assessed? These effects could include benefit for specific industries and disadvantage for others, and increased comparative advantage for local versus distant suppliers. These effects are not amenable to cost-effectiveness analysis but rather need to be investigated through macroeconomic models.

- Could sustainable cities, with lower resource use and reduced greenhouse-gas emissions, achieve equivalent or improved social goals compared with those that consume higher amounts of resources? Moreover, this raises questions about what type of cities we want to live in and how we want to live within them.

- Not all health gains and losses can be quantified, so the monetary values will represent only a part of the full set of health gains and losses from the various social, economic, and technological ramifications of the initial intervention.

For these reasons, we have not attempted to undertake a cost-benefit analysis of all the options, and a systematic cost-effectiveness analysis has not been possible to do, at least at this stage of the research programme, for each of the various mitigation actions. Meanwhile, the cost-effectiveness of the mitigation action can be assessed for strategies for which estimates of cost can feasibly be developed. ${ }^{8}$ Every mitigation activity can be assessed, at least in theory, in terms of cost per unit of health gain and per unit of reduction in greenhouse-gas emissions. 
Panel 2: Uncertainties in estimation of co-benefits to health

Even for specific causal pathways, important sources of uncertainty arise in relation to exposure-response functions (both parameters and mathematical form) and the extent to which exposures would in fact change. In this Series, we have shown some of these uncertainties-eg, use of confidence intervals for exposure-response indices in the food and agriculture paper, ${ }^{5}$ and contrasting different models for effects of particulate pollution in the transport and electricity papers. ${ }^{4.6}$ We have not routinely calculated summaries of uncertainty such as confidence intervals, because doing so would inevitably capture only some sources of uncertainty, and thus give only a partial picture. However, we have quantified effects only when evidence for them is strong, and thus we believe that they provide estimates of the broad magnitude and direction of effects.

Our analyses omit several important pathways by which mitigation strategies for climate change might affect health, such as the effect of fuel prices and conversely the effect of providing equitable access to clean energy for resource-poor populations. We also did not consider the health effects of reducing the extent of climate change, which is the topic of other work.

The timing in which the potential benefits to health from strategies to reduce greenhouse-gas emissions are manifested will vary. These benefits include likely immediate reductions in acute respiratory infections in children from decreases in indoor air pollution in low-income countries, short-term and medium-term reductions in cardiovascular disease incidence and mortality that might occur over a period of years, and reductions in cancer incidence and mortality related to obesity that might take place over decades. Potential health benefits can therefore be regarded as committed benefits that can accrue over variable time spans dependent on the health outcome. The distribution of change in exposure will usually vary between individuals and between regions, economies, and cultures; homogeneous change in the actual dose received is unlikely. Additional important uncertainties are the speed and completeness of any intervention, but especially those needing substantial behavioural change and those needing much investment and political will.

mortality in its own right, which is further supported by the new study. It also damages crops and ecosystems. Future analyses of co-benefits need to consider ozone creation and its effects in detail.

\section{Policy implications}

Estimation and comparison of ancillary health effects is, unavoidably, imprecise. Nevertheless, it benefits from developments in the discipline of impact science (eg, WHO's Comparative Quantification of Health Risks ${ }^{11}$ and assessments of the health effects of power generation in Europe $\left.^{12}\right)$. Despite many scientific uncertainties (panel 2), the models provide useful evidence about the type and approximate scale of health effects that can be expected from pursuit of major mitigation policies. The finding of generally positive health effects of mitigation shows that strategies promoting a low greenhouse-gas emission economy can also have potential to improve public health. ${ }^{13}$ It also provides a rationale to reduce greenhouse-gas emissions that is not wholly confined to the achievement of climate change mitigation. Some commentators suggest that many features of climate change are now irreversible and that the most important objective is to try to adapt to it and other global environmental threats. ${ }^{14}$ However, the case for mitigation is greatly strengthened if it has direct collateral benefits in addition to restriction of climate change.

Much of the disease burden in the poorest countries is still due to category I conditions, which are dominated by infectious and parasitic diseases, maternal mortality, adverse pregnancy outcomes, and malnutrition. ${ }^{15}$ However, the risk factors for non-communicable diseases and consequent category II burdens are rising in many low-income countries. ${ }^{16}$ Rapid urbanisation, industrialisation, and growth of motor transport have resulted in levels of fine particles and ozone that greatly exceed health-based international guidelines, ${ }^{17}$ despite air quality management efforts that have reduced levels of air pollution in some locales. Further, as low-income societies modernise, the risks of inactivity and a transition away from traditional diets (eg, obesity) are emerging quickly, especially in urban populations in which population growth and congregation are great. The apparent rise in the importance of non-communicable disease is also partly due to its unmasking, as the infectious disease burden falls and the global population ages. ${ }^{18}$

Activities for climate change mitigation would in a few cases also directly reduce, via co-benefits, the risks of infectious diseases in low-income countries. An example presented in this Series is that of the reduced incidence of acute lower respiratory infection with improved combustion efficiency or switching to clean fuels for household cooking in poor populations. ${ }^{3}$ Indeed, as shown in the household energy paper, ${ }^{3}$ a full-scale cookstove intervention in India could reduce deaths attributable to acute lower respiratory infection, the main cause of child mortality worldwide, by nearly a third by 2020. Present estimates suggest that indoor air pollution is responsible for more than $2 \%$ of the entire world burden of disease, or close to $4 \%$ in the poorest countries. ${ }^{11}$ Furthermore, evidence of effects of household air pollution on several other health outcomes, including low birthweight and cataracts, is growing, potentially adding to this total. ${ }^{19}$

This Series has not included assessments of all important strategies to reduce greenhouse-gas emissions. One strategy not included is the reduction in population growth, from which potentially major additional health co-benefits would result from provision 


\section{Panel 3: Research priorities}

A recent WHO publication outlined the need for expansion of research into health and climate change encompassing effects, vulnerability, adaptation, and mitigation. ${ }^{26}$ The analyses presented in this Series might be improved through extension in scope, detail, and methodological and data refinements. Further work might complement other efforts at integrated assessment modelling-eg, EC4MACS, a European Consortium for Modelling of Air Pollution and Climate Strategies funded through the EU-LIFE programme.

During our own programme of research and modelling, several topics were identified for which additional research is needed to reduce uncertainties and clarify the potential of greenhouse-gas reduction strategies to improve (or in some cases worsen) health. These issues are listed below.

\section{Cross-cutting issues}

- Costs of implementation of mitigation strategies with substantial health benefits

- Visioning and modelling of the broader economic and social effects of the transition to low-carbon futures

- Closer linkage of climate mitigation strategies to major health targets, such as those in the Millennium Development Goals

- Modelling uncertainties, including timing of exposure and health effects

- The effect of global population growth, including issues of socioeconomic equity and immigration

- Complete accounting of climate and health effects of non-carbon-dioxide greenhouse pollutants

- Assessment of combined mitigation and adaptation strategies

- Alternative methods to the Comparative Risk Assessment approach, strategies for dealing with double-counting of health effects

(Continues in next column)

of universal access to reproductive health services. ${ }^{20}$ The increased birth spacing and reduced fertility that results when women have access to education and contraceptives to control their reproduction can create major health benefits by reducing both maternal and child mortality. ${ }^{21}$ Achievement of these benefits is not a matter of coercion, but of provision of the same level of reproductive health services that women already have in more than half the world. Although the exact effect on greenhouse-gas emissions is not easily measured, bringing the world to replacement fertility sooner rather than later will undoubtedly reduce effects on the planet in the long term. Although per head emissions are low in many resource-poor countries, population growth is projected to increase in coming decades in some high-emitting countries such as the UK and USA, ${ }^{22}$ thus making the attainment of deep cuts in greenhouse-gas emissions in these countries even more challenging.
(Continued from previous column)

\section{More specific to task groups}

- Identify additional mitigation efforts across a wider set of sectors with substantial health effects

- Additional primary research into the short-lived greenhouse pollutants, particularly to understand the effect of sulphate concentrations on climate cooling and health, and the negative effects of black carbon, organic carbon, and ozone on health and climate

- Exploration of sensitivity to assumptions: time discounting, exposure models, and anticipated changes in health over time in pollution-health models

- Use of refined air-pollution emission-dispersion models to estimate concentration changes by country to yield country-specific estimates of health effects, building on integrated assessment approaches such as those from the Network for Integrated Assessment Modelling

- Exploration of methods to characterise economic effects on health due to changes in fuel prices

- Detailed exploration and model development for indoor particulate matter $\left(\mathrm{PM}_{2.5}\right)$ and radon concentrations and associated health effects

- Further exploration of the performance of household ventilation systems and associated health effects

- Further accounting of different types of saturated fat from animal products (eg, stearic, palmitic, myristic)

- Health impact assessment of new and emerging greenhouse-gas mitigation technologies such as carbon capture and storage and geoengineering schemes such as emissions of sulphates from non-combustion sources

- Potential for climate change and mitigation strategies to affect crop production and risk of hunger

A controversial approach to mitigation is the production of biofuels, particularly to meet growing demands for liquid fuels for transport. Many factors affect greenhousegas emissions from the biofuels supply system, such as the inputs of energy used to grow the plants from which they are derived and land-use change as a result of growing plants for biofuels. There has been particular concern that production of ethanol from corn needs substantial fossil fuel and fertiliser, thus resulting in large emissions of both greenhouse gases and fine particulates. ${ }^{23}$ Biofuels could potentially make an important contribution to reductions in greenhouse gases if they came from "feedstocks produced with much lower life-cycle greenhouse-gas emissions than traditional fossil fuels and with little or no competition with food production". ${ }^{24}$ For meeting transportation needs though, recent evidence suggests that combustion of biomass to generate electricity for charging battery-powered vehicles outperforms ethanol in terms of land-use efficiency and greenhouse-gas emissions offsets per unit area of crops. ${ }^{25}$ The potential implications of biofuels and bioenergy for health and harmful emissions need further investigation.
For more about the European Consortium for Modelling of Air Pollution and Climate Strategies see http://www. ec4macs.eu/home/index.html

For more about the Network for Integrated Assessment Modelling see http://www.niam. scarp.se/ 
Panel 4: Action points

Policy makers in sectors that are responsible for substantial greenhouse-gas emissions should:

- Take into account health co-benefits and potential harms when considering different mitigation options for greenhouse gases so that they enhance progress towards the Millennium Development Goals and other health and development priorities

- Ensure that new technologies and strategies for greenhouse-gas mitigation are subject to health impact assessment before being disseminated

- Implement policies to reduce inequities in access to clean energy sources

- Consider removal of subsidies that encourage the consumption of animal products in high-consuming nations

- Increase expenditure for measures to encourage cycling and walking and discourage private-car use in urban centres

Research funders should:

- Increase funding for interdisciplinary collaboration, including methods development, between health researchers and scientists working on climate change mitigation technologies and strategies across several sectors

- Build capacity by supporting the career development and training of researchers in relevant disciplines

- Promote strategies and policies for low greenhouse-gas emissions in their own working environment and in their allocation of funding

Health policy makers should:

- Promote and support policies to achieve low greenhouse-gas emissions while delivering co-benefits to health and encourage simple behavioural changes that result in reduction of greenhouse gases

- Ensure that the health workforce is encouraged to reduce their personal greenhouse-gas emissions, including through increased active transport

Health professionals should:

- Advocate for policies to reduce greenhouse-gas emissions and achieve health co-benefits on the basis of the best available evidence

- Promote education on this topic in schools, universities, and the wider community

- Promote strategies and policies to lower greenhouse-gas emissions in their own working environment
1992). ${ }^{27}$ Benefits to health readily attract public support for political action, as shown by experiences in which health benefits have dominated the externalities of environmental interventions such as clean air legislation in many countries.

The Clean Development Mechanism emerged from the Kyoto Protocol, ${ }^{27}$ and established mechanisms for trading of carbon permits. Although low-income and middle-income countries were exempt from the binding requirements on Annex 1 (industrialised) countries to achieve specific cuts in greenhouse-gas emissions, these countries can, at least theoretically, benefit by selling carbon credits, for projects that will enhance their sustainable development. Although the Clean Development Mechanism has made some contribution in channelling funds to beneficiary nations, difficulties have arisen, ${ }^{28}$ including the absence of an effective standard way to quantify the extent of development in such a project, or to choose one project over another according to how much development it achieves. Thus, although the mechanism was meant to lend support to sustainable development, approved projects have largely focused on greenhouse-gas mitigation, with some consideration of employment. Further, data from $2006^{28}$ showed that only a few projects have benefited in sub-Saharan Africa (1.8\%), whereas Asian countries (particularly China) have had much more success. The Nairobi Framework initiative was launched in November, 2006, with the support of the UN, World Bank, and African Development Bank to foster participation of poor countries, particularly in Africa. ${ }^{29}$

Achievement of a reasonable health status within populations is an essential element in development, as is recognised by almost every country in the form of the MDGs. ${ }^{2}$ Although not without uncertainties, we believe that the assessment of the health co-benefits of climate mitigation projects is sufficiently advanced to allow estimation of the magnitude of their effects. We propose therefore that assessment of the health co-benefits of projects submitted to the Clean Development Mechanism and other such international efforts should be one criterion of suitability for funding. Indeed, the establishment in 2007 of the MDG-Carbon Facility by UN Development Programme, UN Foundation, and others suggests a potential mechanism through which this effort could begin. ${ }^{30}$ Our work could contribute to development of standardised approaches for assessment of health and development co-benefits.

\section{Bridging of the equity divide}

A major difficulty in international greenhouse-gas negotiations is the difference in historical and future perspectives between rich and poor countries. Observers in low-income countries point out that the historical activities in rich countries have caused most climate change so far. ${ }^{31}$ Since low-income countries have many urgent needs for development, they do not see mitigation 
of their own greenhouse-gas emissions as a high priority at present. Yet, if climate change is to be brought under control, in addition to urgent and far-reaching reductions in high-income countries, there will also soon be a need for many low-income and middle-income countries to take mitigation action.

Policies to promote mitigation activities that have strong co-benefits in health and other development needs provide a potential political bridge across the development gap between rich and poor countries. These initiatives would directly address the major needs of development, with recognition of the imperatives of climate change. Indeed, the provision of affordable clean household energy in developing countries can contribute to the attainment of all eight MDGs, both through the co-benefits to health and through contributions to poverty reduction, provision of productive work, reduction of unproductive time, and thereby reduction of gender inequities. ${ }^{32}$

Considerations of intergenerational equity will also apply, for at least some of the decisions about mitigation actions. For example, if present trends in animal production methods and per head animal-product consumption continue, today's generation will bequeath to future generations a more impoverished and damaged natural environment than at present. Conversely, reformation of urban layout and changes in city planning and housing standards can create, over several decades, an infrastructural base yielding life-long enduring benefits to present and future generations.

\section{Call to action and conclusions}

In panel 4 we summarise the implications for several stake-holder groups of the evidence from this Series. Health improvement (via both co-benefits and the avoidance of health effects related to climate change) needs to be integrated into policies to reduce greenhouse-gas emissions and the risk of dangerous climate change. We call on health professionals to reach beyond conventional professional boundaries to collaborate with policy makers and scientists concerned with the study, development, and implementation of policies and technologies to mitigate climate change.

This Series makes clear that health co-benefits can accrue as a direct result of many mitigation activities for greenhouse-gas emissions. If societies change their energy systems in ways that improve outdoor and indoor air quality, change their methods of transport in ways that encourage physical activity and social contact, and modify intensive food production practices and consumer choices in ways that reduce dietary risks to health, then many positive health consequences will result. Despite uncertainties about the magnitude and timescale, health co-benefits from mitigation can be anticipated. Therefore, commitment to mitigation actions producing many such benefits becomes very appealing, especially if (as is likely) the health gains entail substantial national cost savings as an offset to the costs of the mitigation actions. The strategic significance of this issue is potentially great. If the health co-benefits from mitigation activities in lower-income countries were sufficiently large, it would strengthen the rationale for achieving convergence of mitigation schedules between low-income and high-income countries.

The potential co-benefits from selected mitigation measures for greenhouse-gas emissions should heighten the profile of health as a criterion in discussions at the Climate Change Conference in Copenhagen, Denmark, in December, 2009. So far, awareness of the importance and long-term significance of health to the challenges of climate change has been low. Health professionals therefore have an important role in educating the public and policy makers about the health aspects of climate change, including the potential health co-benefits of mitigation measures for greenhouse gases. ${ }^{33}$

As countries consider reductions in their own greenhouse-gas emissions or whether to invest in clean development, the health co-benefits (and potential negative health consequences) should be weighed up carefully in advance. Further research, methodological development, and analytical work are needed to improve prioritisation of mitigation in different sectors and regions. Since trillions of dollars are likely to be spent on greenhouse-gas mitigation in the next decades, it is essential to allocate the fairly small research resources that are needed to guide these investments along paths that bring the world closer to both its health and climate goals.

\section{Contributors}

AH chaired the Task Force. All authors participated in the development of ideas for their papers. The text of this paper was drafted mainly by AJM, AH, KRS, and PW, with contributions from all other authors.

\section{Task Force on Climate Change Mitigation and Public Health}

London School of Hygiene and Tropical Medicine, London, UK Andy Haines (chairman), Ben G Armstrong, Zaid Chalabi, Alan D Dangour, Phil Edwards, Karen Lock, Ian Roberts, Cathryn Tonne, Paul Wilkinson, James Woodcock; American Cancer Society, Atlanta, GA, USA Michael J Thun; BC3 (Basque Centre for Climate Change), Bilbao, Spain Aline Chiabai, (also at University of Bath) Anil Markandya; Brigham Young University, Provo, UT, USA C Arden Pope III; Edinburgh Napier University, Edinburgh, UK Vicki Stone; Food Climate Research Network, University of Surrey, Surrey, UK Tara Garnett; Health Canada, Ottawa, ON, Canada Richard T Burnett; Health Effects Institute, Boston, MA, USA Aaron Cohen; Indian Institute of Technology, Delhi, India Ishaan Mittal, Dinesh Mohan, Geetam Tiwari; Imperial College London, London, UK Richard Derwent; King's College London, Environmental Research Group, London, UK Sean Beevers; London International Development Centre, London, UK Jeff Waage; National Centre for Epidemiology and Population Health, The Australian National University, Canberra, ACT, Australia Ainslie Butler, Colin D Butler, Sharon Friel, Anthony J McMichael; New York University School of Medicine, New York, NY, USA George Thurston; San Diego State University, Graduate School of Public Health, San Diego, CA, USA Zohir Chowdhury; St George's, University of London, Division of Community Health Sciences, and MRC-HPA Centre for Environment and Health, London, UK H Ross Anderson, Richard W Atkinson, Milena Simic-Lawson; Takedo International, London, UK Olu Ashiru; University of Auckland, School of Population Health, Auckland, New Zealand Graeme Lindsay, Alistair Woodward; University of California, Berkeley, School of Public Health, Berkeley, CA, USA Heather Adair, Zoe Chafe, Michael Jerrett, Seth B Shonkoff, Kirk R Smith; University College London, Bartlett School of Graduate 
Studies, London, UK Michael Davies, Ian Hamilton, Ian Ridley; University College London, Energy Institute, London, UK Mark Barrett, Tadj Oreszczyn; University of Grenoble and CNRS (Centre Nationale de la Recherche Scientifique), Grenoble, France Patrick Criqui, Silvana Mima; University of Liverpool, Division of Public Health, Liverpool, UK Nigel Bruce; University of Oxford, School of Geography and the Environment, Centre for the Environment, Oxford, UK David Banister, Robin Hickman; University of Ottawa, Ottawa, ON, Canada Daniel Krewski; University of Warwick, Health Sciences Research Institute, Coventry, UK Oscar H Franco; World Health Organization, Geneva, Switzerland Simon Hales, Diarmid Campbell-Lendrum.

Conflicts of interest

We declare that we have no conflicts of interest.

\section{Acknowledgments}

The project that led to this Series was funded by the Wellcome Trust (coordinating funder); Department of Health, National Institute for Health Research; the Royal College of Physicians; the Academy of Medical Sciences; the Economic and Social Research Council; the US National Institute of Environmental Health Sciences; and WHO. The Royal College of Physicians was supported by an unrestricted educational grant from Pfizer. The funders had no role in the design, analysis, or interpretation of the study. The views expressed are those of the authors and do not necessarily reflect the position of the funding bodies or the US Health Effects Institute or its sponsors.

References

1 Haines A, Kovats RS, Campbell-Lendrum D, Corvalan C. Climate change and human health: impacts, vulnerability, and mitigation. Lancet 2006; 367: 2101-09.

2 United Nations. Millennium Development Goals Report 2009. New York: United Nations, 2009.

3 Wilkinson P, Smith KR, Davies M, et al. Public health benefits of strategies to reduce greenhouse-gas emissions: household energy. Lancet 2009; published online Nov 25. DOI:10.1016/S01406736(09)61713-X.

4 Woodcock J, Edwards P, Tonne C, et al. Public health benefits of strategies to reduce greenhouse-gas emissions: urban land transport. Lancet 2009; published online Nov 25. DOI:10.1016/S01406736(09)61714-1.

5 Friel S, Dangour AD, Garnett T, et al. Public health benefits of strategies to reduce greenhouse-gas emissions: food and agriculture. Lancet 2009; published online Nov 25. DOI:10.1016/S01406736(09)61753-0.

6 Markandya A, Armstrong BG, Hales S, et al. Public health benefits of strategies to reduce greenhouse-gas emissions: low-carbon electricity generation. Lancet 2009; published online Nov 25. DOI:10.1016/ S0140-6736(09)61715-3.

7 Smith KR, Jerrett M, Anderson HR, et al. Public health benefits of strategies to reduce greenhouse-gas emissions: health implications of short-lived greenhouse pollutants. Lancet 2009; published online Nov 25. DOI:10.1016/S0140-6736(09)61716-5.

8 Smith KR, Haigler E. Co-benefits of climate mitigation and health protection in energy systems: scoping methods. Ann Rev Public Health 2008; 29: 11-25.

9 Dobson R. GPs to be creative in prescribing exercise (news). BMJ 2009; 339: 417

10 Butland B, Jebb S, Kopelman P, et al. Foresight. Tackling obesities: future choices-project report. London: Government Office for Science, 2007.

11 Ezzati M, Rodgers A, Lopez A, Murray C, eds. Comparative quantification of health risks: global and regional burden of disease due to selected major risk factors. Geneva: World Health Organization, 2004

12 European Commission. ExternE: externalities of energy: methodology 2005 update. EUR 21951. Brussels: European Commission, 2005.
13 Haines A, Smith KR, Anderson D, et al. Policies for accelerating access to clean energy, improving health, advancing development, and mitigating climate change. Lancet 2007; 370: 1264-81.

14 Lovelock J. The vanishing face of Gaia: a final warning. London: Allen Lane, 2009.

15 Ezzati M, Lopez A, Rodgers AD, Vander-Hoorn S, Murray CJL, for the Comparative Risk Assessment Collaborating Group. Selected major risk factors and global and regional burden of disease. Lancet 2002; 360: 1347-60.

16 Mathers CD, Loncar D. Projections of global mortality and burden of disease from 2002 to 2030. PLoS Med 2006; 3: e442.

17 WHO. WHO air quality guidelines-global update 2005. Copenhagen: World Health Organization, 2006.

18 Smith KR, Ezzati M. How environmental health risks change with development: the epidemiologic and environmental risk transitions revisited. Ann Rev Environ Res 2005; 30: 291-333.

19 Lin H, Ezzati M, Murray M. Tobacco smoke, indoor air pollution and tuberculosis: A systematic review and meta-analysis. PLoS Med 2007; 4: 1-17.

20 Smith KR, Balakrishnan K. Mitigating climate, meeting MDGs, and moderating chronic disease: the Health Co-benefits Landscape Commonwealth Health Ministers' Update 2009. London: Commonwealth Secretariat, 2009: 59-65.

21 Rutstein SO. Effects of preceding birth intervals on neonatal, infant and under-five years mortality and nutritional status in developing countries: evidence from the demographic and health surveys. Int J Gynaecol Obstet 2005; 89 (suppl 1): S7-24.

22 US Census Bureau. Population by region and country: 1950-2050 http://www.census.gov/ipc/prod/wp02/tabA-04.xls (accessed Sept 30, 2009).

23 Hill J, Polasky S, Nelson E, et al. Climate change and health costs of air emissions from biofuels and gasoline. Proc Natl Acad Sci USA 2009; 106: 2077-82.

24 Tilman D, Socolow R, Foley JA, et al. Beneficial biofuelsthe food, energy, and environment trilemma. Science 2009; 325: 270-71.

25 Campbell JE, Lobell DB, Field CB. Greater transportation energy and GHG offsets from bioelectricity than ethanol. Science 2009; 324: 1055-57.

26 WHO. Protecting health from climate change. Global research priorities. Geneva: World Health Organization, 2009.

27 UNFCCC. UN Framework Convention on Climate Change. Full text of the convention. New York: United Nations, 1992. http://unfccc.int/kyoto_protocol/items/2830.php (accessed Sept 30, 2009).

28 Boyd E, Hultman NE, Roberts T, et al. The Clean Development Mechanism; an assessment of current practice and future approaches to policy Norwich: Tyndall Centre for Climate Change Research, 2007.

29 United Nations Framework Convention on Climate Change. The Nairobi Framework - catalysing the CDM in Africa. UNFCCC, 2009. http://cdm.unfccc.int/Nairobi_Framework/index.html (accessed Sept 30, 2009).

30 UNDP. MDG-Carbon Facility, 2008. http://www.mdgcarbonfacility. org/ (accessed Sept 30, 2009).

31 Marland G, Boden TA, Andres RJ. Global, regional, and national fossil fuel $\mathrm{CO}_{2}$ emissions. In: Trends: a compendium of data on global change. Carbon Dioxide Information Analysis Center, Oak Ridge: Oak Ridge National Laboratory, US Department of Energy, 2007.

32 Wilkinson P, Smith KR, Joffe M, Haines A. A global perspective on energy: health effects and injustices. Lancet 2007; 370: 965-78.

33 Griffiths J, Rao M, Adshead F, Thorpe A. Health practitioners guide to climate change. London: Earthscan, 2009. 